\title{
USE OF POWER METHOD FOR IDENTIFICATION OF NONLINEARITY PARAMETERS
}

\author{
M. Zagirnyak, D. Mosiundz, D. Rodkin \\ Institute of Electromechanics, Energy Saving and Control Systems, \\ Kremenchuk Mykhailo Ostrohradskyi National University, \\ 20, Pershotravneva Street, Kremenchuk, Ukraine. \\ e-mail: mzagirn@kdu.edu.ua, e-mail: darya_mosyundz@mail.ru
}

Procedure of calculation of nonlinearity parameters by power method based on equations of balance of the source and consumer instantaneous powers components according to each separate harmonic is proposed. It is demonstrated that such an approach makes it possible to obtain the required number of equations for determination of the nonlinearity parameters. The method is verified using the example of calculation of parameters of a simple electric circuit with a nonlinear inductance. References 12, figures 6.

Keywords: nonlinear element, instantaneous power, power method, equations of instantaneous power components balance.

Introduction. The analysis of electromagnetic and power processes in electric circuits is based on the known laws of Kirchhoff, Ohm, postulates following from Tellegen theorem [1] and, first of all, equality of the powers of the source and the consumer. The latter is most often used in estimation of the correspondence of the obtained results to energy conservation law.

Two typical problems are singled out of the tasks of identification of electric circuit parameters:

- the problem of determination of voltages, currents and powers of different elements of circuits when their parameters are assigned;

- the problem of finding values of parameters of certain elements, e.g. sources electromotive forces (EMF) providing supply of the required voltages, currents or powers.

The paper deals with the second problem for nonlinear elements. The main difficulty of the analysis of such circuits consists in the necessity of taking into account the dynamic properties of the nonlinear element itself and its influence on the system as a whole. So, for example, it is known that during operation of a nonlinear element the alternating current in the circuit becomes nonsinusoidal and contains harmonic components divisible by the frequency of the supply mains [2].

When parameters of circuits with nonlinearities are calculated, the solution of the problem is hampered by limitation of the number of initial equations when there are a great number of unknowns. Electric machines equivalent circuits containing a nonlinear inductance are a particular case of such circuits.

Many authors dealt with calculation of such circuits [3 - 6]. However, offered principles are based on rather lengthy and not always accurate calculation methods. Besides, relations used in these methods often do not correspond to real power processes in these circuits.

The known methods of calculation of electric circuit elements parameters are divided into numerical and analytical ones. Use of numerical methods [3] allows solution of equation systems with many unknowns. However, it is connected with an approximate determination of roots of equations or equation systems and is applied in the cases when the exact method of solution is unknown or laborious [4]. In particular, finite element method (FEM) is often used in solution of such problems [5]. One of its drawbacks consists in the necessity of boundary conditions. They are chosen by special methods.

As to analytical methods, harmonic analysis of electric circuits, in particular with nonlinear elements, is widely spread now. However, this method described in papers $[6,7]$ is based on linearization of nonlinear processes. The fault of such methods consists in taking into consideration only the first harmonic when output parameters of a system with nonlinear characteristics is described, but harmonic components of higher frequencies directly characterizing the nonlinear element influence on the system are neglected.

As there is no simple and efficient method of analysis of electric circuits with nonlinear characteristics, creation of a calculation procedure making it possible to obtain the necessary accuracy of calculation and take into account the special features of physical processes in nonlinear circuits is topical.

(C) Zagirnyak M., Mosiundz D., Rodkin D., 2017 
Problem statement. The purpose of the research carried out in the paper consists in development of a calculation procedure for parameters of nonlinearity of alternating current electric circuits using a power method, verification of its availability by example of calculation of parameters of nonlinear inductance.

General theses of the power method in problems of identification. It was found out by research that the theses of Tellegen theorem are transformed into equations of balance of power of separate harmonics, obtained as a result of frequency analysis of power function $p(t)$ equal to the product of time $t$ signals of voltage $u(t)$ and current $i(t)$ [8]. Transition from equations of electric balance to equations of power balance separately for every power harmonic for its constant and variable components allows essential improvement of the possibilities of calculation by increase of the number of identification equations. In this case balance equations formulated separately for constant, active and reactive power components can be used as parity-check equations.

If current and voltage are decomposed into harmonic components:

$$
\begin{aligned}
& i(t)=\sum_{m=0}^{\infty}\left(I_{m a} \cos (m \Omega t)+I_{m b} \sin (m \Omega t)\right), \\
& u(t)=\sum_{n=0}^{\infty}\left(U_{n a} \cos (n \Omega t)+U_{n b} \sin (n \Omega t)\right),
\end{aligned}
$$

then the obtained number $K$ of the equations corresponds to the number of the analyzed harmonics of current $m$ and voltage $n$. Total number of identification equations will make $K=2 m+1=2 n+1$, which may be insufficient when the number of unknowns is great.

In (1), (2) $n, m-$ number correspondingly of voltage and current harmonics; $I_{m a}, I_{m b}$ - correspondingly cosine and sine amplitude components of current harmonics; $U_{n a}, U_{n b}$ - correspondingly cosine and sine amplitude components of voltage harmonics.

Number of equations in harmonic analysis of power function

$$
p(t)=u(t) i(t)=\sum_{k=0}^{\infty}\left(P_{k a} \cos (k \Omega t)+P_{k b} \sin (k \Omega t)\right)
$$

is significantly larger, as series of voltage with number $n$ of harmonics are multiplied by current with number $m$ of harmonics. It results in $(m \cdot n)$ harmonic components of power and $K=2(n+m)$ power balance equations. It considerably exceeds the number of equations of electric balance that can be formulated with the use of the theses of electrical engineering theory.

Thus, processes in alternating current nonlinear circuits can be described by systems of power balance equations obtained from Tellegen theorem on the basis of electric balance equations. This approach was the basis for a proposed power method [9] used in calculation of complicated electric circuits on the grounds of harmonic analysis of the curves of voltage, current and power. The offered method makes it possible to present processes of energy conversion in nonlinear elements more reliably and obtain calculation relations for

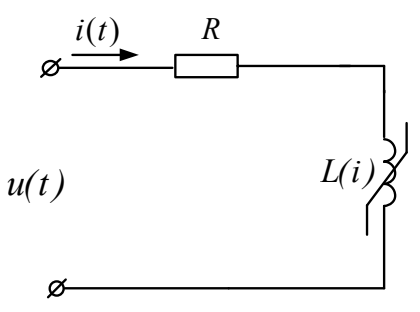

Fig. 1 determination of their parameters on the basis of power criteria [10].

Procedure of calculation of nonlinear inductance parameters is described on the basis of analysis of a simple electric circuit (Fig. 1) containing an alternating current power supply with voltage $u(t)=U_{1 a} \cos (\Omega t)$, resistance $R$, nonlinear inductance $L(i)$. Here $U_{1 a}$ - amplitude value of the first harmonic of voltage, $\Omega$ - angular frequency.

Fig. 2 shows the character of dependences of induction $B$ and coil inductance $L$ as functions of current $i$ flowing thorough winding turns.

The given dependences can be approximated in a general case by power polynomials. Taking into account their special features and presence of symmetry of a certain type (see Fig. 2), there is every reason to believe that there is no constant component and the influence of components at even powers of current $i$ in dependence $B(i)$ and components at odd powers of current in dependence $L(i)$ is insignificant. It allows one to neglect the

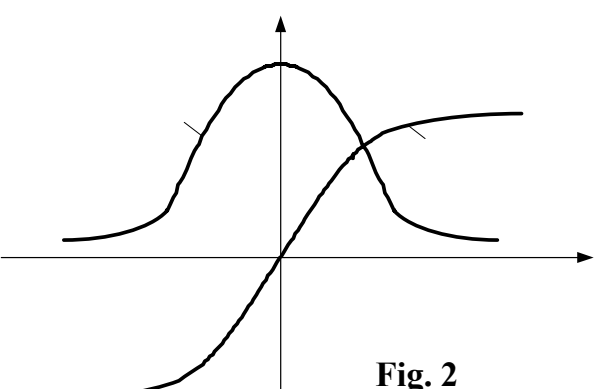

Fig. 2 mentioned components in approximating expressions. 
Thus, if the operation condition of the circuit includes core saturation zone, dependence $B(i)$ can be presented in the form

$$
B(i)=a_{1} i+a_{3} i^{3}+a_{5} i^{5}+\ldots+a_{b} i^{b},
$$

and inductance $L$ dependence on current $i$ will be

$$
L(i)=b_{0}+b_{2} i^{2}+b_{4} i^{4}+\ldots+b_{l} i^{l}
$$

where $a_{1}, a_{3}, a_{5}, \ldots, a_{b}, b_{0}, b_{2}, b_{4}, \ldots, b_{l}$ - approximation coefficients; $b$ and $l$-assumed maximum degrees of approximating polynomials.

It was demonstrated by the authors $[11,12]$ that such a representation is a universal one and describes behavior of this curve most accurately. In those curves the calculation is based on a typical symmetrical magnetizing curve $B(i)$ (Fig. 2) characterized by change of inductance with double frequency compared with frequencies of current components determining the process of material reversal magnetization.

If instead of current $i$ its dependence (1) on time is substituted into (5), transfer from $L(i)$ to time dependence $L(t)$ will be obtained:

$$
L(i(t))=b_{0}+b_{2} i^{2}(t)+b_{4} i^{4}(t)+\ldots+b_{l} i^{l}(t) .
$$

Coefficients $b_{0}, b_{2}, b_{4}, \ldots, b_{l}$ in (3) are unknowns.

Such a representation makes it possible to consider inductance $L$ as varying depending on current, time and also on both these parameters simultaneously. of the form

Taking the above said into consideration, expression (6) for a simple electric circuit (Fig. 1) will be

$$
\begin{aligned}
& L(i(t))=b_{0}+b_{2}\left(\sum_{m=0}^{\infty}\left(I_{m a} \cos (m \Omega t)+I_{m b} \sin (m \Omega t)\right)\right)^{2}+ \\
& +b_{4}\left(\sum_{m=0}^{\infty}\left(I_{m a} \cos (m \Omega t)+I_{m b} \sin (m \Omega t)\right)\right)^{4}+\ldots+ \\
& +b_{l}\left(\sum_{m=0}^{\infty}\left(I_{m a} \cos (m \Omega t)+I_{m b} \sin (m \Omega t)\right)\right)^{l} .
\end{aligned}
$$

After relevant transformations the following will be obtained:

$$
L(i(t))=L_{0}+\sum_{k=0}^{\infty}\left(L_{k a} \cos (k \Omega t)+L_{k b} \sin (k \Omega t)\right)=L_{0}+L^{\prime}(i(t)) .
$$

In (7) and (8) $L_{0}=b_{0}+f\left(b_{2} ; b_{4} ; \ldots ; b_{l} ; I_{m a} ; I_{m b}\right), k$ - number of harmonics of inductance amplitude components obtained as a result of mathematical transformations of expression (7); $L_{k a}, L_{k b}-$ amplitude values of inductance for $k$-th harmonic cosine and sine components, respectively; $L^{\prime}(i(t))$ - inductance variable component.

It can be seen from (8), that constant component $L_{0}$ includes component $b_{0}$ (inductance value when current equals to zero) and a function of variable components.

When power processes directly connected with $L^{\prime}(i(t))$ are analyzed, equivalent circuit (Fig. 3), in which constant $L_{0}$ and variable $L^{\prime}(i(t))$ inductance components are considered separately, is true. In this circuit $L^{\prime}(i(t))$ is presented as equivalent to EMF characterizing physical demonstration of nonlinearity, i.e. formation of harmonics divisible by current harmonics. Such substitution of a variable component, equivalent to EMF, allows one to simplify the calculation and explain the mechanism of energy conversion at nonlinear inductance: active power is consumed only as a part of single-frequency components (i.e. only when voltage and current frequencies are equal), and occurrence of current high-frequency components is caused by energy conversion process in a nonlinear element.

Expression of EMF will be of the form:

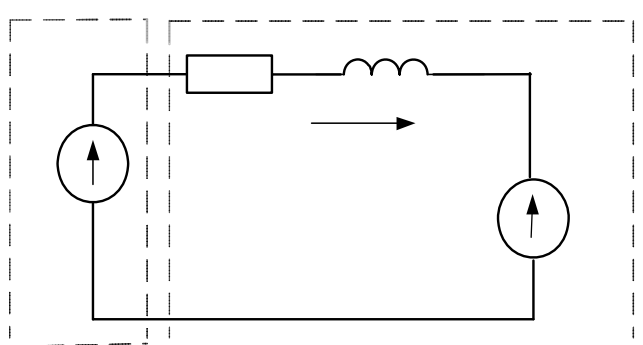

Fig. 3 


$$
E(t)=\frac{d}{d t}\left(L^{\prime}(i(t)) i(t)\right)=\sum_{m=0}^{\infty}\left(E_{m a} \cos (m \Omega t)+E_{m b} \sin (m \Omega t)\right),
$$

where $E_{m a}, E_{m b}-$ amplitude values for cosine and sine, respectively, components of EMF of $m$-th harmonic.

Expressions for power functions at the circuit elements:

- source power

$$
p(t)=u(t) i(t)=P_{0}+\sum_{k=1}^{\infty}\left(P_{k a} \cos (k \Omega t)+P_{k b} \sin (k \Omega t)\right) ;
$$

- active power component

$$
p_{R}(t)=R i^{2}(t)=P_{0 R}+\sum_{k=1}^{\infty}\left(P_{k a R} \cos (k \Omega t)+P_{k b R} \sin (k \Omega t)\right) ;
$$

- reactive power fixed component

$$
p_{L}(t)=L_{0} \frac{d i(t)}{d t} i(t)=P_{0 L}+\sum_{k=1}^{\infty}\left(P_{k a L} \cos (k \Omega t)+P_{k b L} \sin (k \Omega t)\right) ;
$$

- reactive power variable component

$$
p_{E}(t)=E(t) i(t)=P_{0 E}+\sum_{k=1}^{\infty}\left(P_{k a E} \cos (k \Omega t)+P_{k b E} \sin (k \Omega t)\right),
$$

where in (10)-(13) $P_{0}, P_{0 R}, P_{0 L}, P_{0 E}$ - constant components of instantaneous power, and $P_{k a}, P_{k b}, P_{k a R}, P_{k b R}$, $P_{k a L}, P_{k b L}, P_{k a E}, P_{k b E}-$ cosine and sine amplitude components of $k$-th harmonic of power function of the source, active power component, reactive power fixed component and reactive power variable component, respectively.

An equation system for determination of $L_{0}$ in (8) and amplitude values of EMF components can be obtained from expression

$$
u(t) i(t)=R i^{2}(t)+L_{0} \frac{d i(t)}{d t} i(t)+E(t) i(t) .
$$

According to Tellegen theorem, let us present all the members of this equation in the form of $P_{0}$, $P_{k a} \cos (k \Omega t)$ and $P_{k b} \sin (k \Omega t)$, respectively; then group the coefficients of harmonics of equal order on the right and on the left of the sign of equality. Then, without writing all the intermediate transformations, we will obtain a system of power equations for a constant and amplitude cosine and sine components:

$$
\left\{\begin{array}{l}
P_{0}=P_{0 R}+P_{0 L}+P_{0 E} \\
P_{1 a}=P_{1 a R}+P_{1 a L}+P_{1 a E} ; \\
P_{1 b}=P_{1 b R}+P_{1 b L}+P_{1 b E} ; \\
------------- \\
P_{k a}=P_{k a R}+P_{k a L}+P_{k a E} ; \\
P_{k b}=P_{k b R}+P_{k b L}+P_{k b E}
\end{array}\right.
$$

Having solved (15) we will determine amplitude components of dependence $E(t)$ and a constant component $L_{0}$ of inductance.

Transfer to parameters $L^{\prime}(i(t))$ is made on the basis of equality

$$
E(t)=\frac{d}{d t}\left(L^{\prime}(i(t)) i(t)\right)=L^{\prime}(i(t)) \frac{d i(t)}{d t}+i(t) \frac{d L^{\prime}(i(t))}{d t} .
$$

An equation system for determination of values $L_{k a}, L_{k b}$ will be obtained from expression (16) due to decomposition of each component into harmonics.

Example of determination of nonlinear parameters of an alternating current circuit. Let us consider an electric circuit with parameters: $u(t)=220 \cos (\Omega t) ; \quad \Omega=100 \mathrm{~s}^{-1} ; R=100 \mathrm{Ohm}, \quad b_{0}=1.43$; $b_{2}=-0.4 ; b_{4}=0.07$. To estimate the accuracy of calculation of nonlinear inductance parameters by power method let us create a mathematical model (modeling is performed in software environment Matlab) assuming parameters of nonlinear inductance to be known. As a result of modeling we will obtain voltage and current, taking nonlinearity into account, which will be initial data for formulation of identification 
equations. It will provide the possibility of estimation of a calculation error by comparison of data obtained as a result of mathematical modeling and the ones obtained by the proposed method.

Expression for nonlinear inductance is of the form

$$
L(i(t))=b_{0}+b_{2} i^{2}(t)+b_{4} i^{4}(t)
$$

The model is formed by solution of the differential equation

$$
u(t)=R i(t)+(L(i(t)) i(t)) \frac{d i(t)}{d t} .
$$

For a circuit with the above stated parameters a current time dependence of the following form is obtained:

$$
i(t)=1.37 \cos (\Omega t)-1.01 \sin (\Omega t)+0.08 \cos (3 \Omega t)-0.3 \sin (3 \Omega t)+0.017 \cos (5 \Omega t)-0.085 \sin (5 \Omega t) .
$$

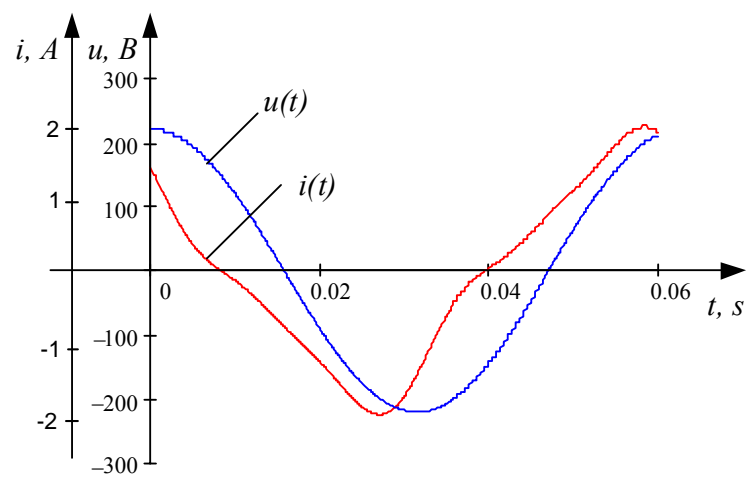

Fig. 4

Fig. 4 shows current and voltage curves obtained as a result of solution of equation (18).

As current contains the first, the third and the fifth harmonics, EMF also contains harmonics with the frequencies of the mains and current frequencies. Expression for EMF is of the form

$$
\begin{aligned}
& E(t)=E_{1 a} \cos (\Omega t)+E_{1 b} \sin (\Omega t)+E_{3 a} \cos (3 \Omega t)+ \\
& +E_{3 b} \sin (3 \Omega t)+E_{5 a} \cos (5 \Omega t)+E_{5 b} \sin (5 \Omega t) .
\end{aligned}
$$

For the further analysis of power processes conditioned by presence of nonlinear inductance a system of equations according to expression (14) is formulated and the values of EMF amplitude components and inductance constant component $L_{0}$ are determined

$$
\left\{\begin{array}{l}
13.55=12.77-0.25 E_{1 a}-0.035 E_{1 b}-0.01 E_{3 a}-0.0055 E_{3 b}-0.00022 E_{5 a}-0.00038 E_{5 b} ; \\
-0.28=13.3+12.28 L-0.26 E_{1 a}+0.029 E_{1 b}-0.25 E_{3 a}-0.035 E_{3 b}-0.01 E_{5 a}-0.0055 E_{5 b} ; \\
53.33=3.9-41.86 L-0.04 E_{1 a}-0.24 E_{1 b}+0.035 E_{3 a}-0.25 E_{3 b}+0.0055 E_{5 a}-0.01 E_{5 b} ; \\
-0.87=0.95+4.55 L-0.01 E_{1 a}+0.005 E_{1 b}-0.25 E_{3 a}+0.35 E_{3 b}-0.25 E_{5 a}-0.035 E_{5 b} ; \\
2.27=0.72-5.96 L-0.0058 E_{1 a}-0.0097 E_{1 b}-0.035 E_{3 a}-0.25 E_{3 b}+0.035 E_{5 a}-0.25 E_{5 b} ; \\
-0.077=0.03+0.59 L-0.0002 E_{1 a}+0.0004 E_{1 b}-0.01 E_{3 a}+0.0055 E_{3 b}-0.25 E_{5 a}+0.035 E_{5 b} \\
0.055=0.063-0.28 L-0.0004 E_{1 a}-0.0002 E_{1 b}-0.005 E_{3 a}-0.01 E_{3 b}-0.035 E_{5 a}-0.25 E_{5 b}
\end{array}\right.
$$

The following parameters are obtained as a result of solution of the system: $E_{1 a}=58.43 \mathrm{~V}$; $E_{1 b}=-435.11 \mathrm{~V} ; E_{3 a}=17.07 \mathrm{~V} ; E_{3 b}=-26.39 \mathrm{~V} ; E_{5 a}=1.53 \mathrm{~V} ; E_{5 b}=-0.45 \mathrm{~V} ; L_{0}=0,8 \mathrm{H}$.

Obviously, value $E_{1 a}$ is positive and values $E_{1 b}, E_{3 b}, E_{5 b}$ are negative. This fact is quite simply explained by the mechanism of power transformation in inductance with saturation. At the first harmonic power is consumed from the mains as supply voltage is sinusoidal. At higher harmonics power is generated. It should be noted that all the power generated by higher harmonics dissipates at resistance.

Taking into account the calculated amplitude values of EMF the system of equations for determination of nonlinearity parameters can be written down according to (20):

$$
\left\{\begin{array}{l}
58.43=9.3 L_{2 a}-75.4 L_{2 b}+1.6 L_{4 a}-3.1 L_{4 b} \\
-435.11=81.6 L_{2 a}+12.7 L_{2 b}+3.2 L_{4 a}+1.84 L_{4 b} \\
17.07=-33.3 L_{2 a}-235.3 L_{2 b}+33 L_{4 a}-235.5 L_{4 b} \\
-26.39=235.7 L_{2 a}-32.6 L_{2 b}+235.5 L_{4 a}+33 L_{4 b}
\end{array}\right.
$$

As a result of solution of system (22) the following parameters are obtained: $L_{2 a}=0.2 \mathrm{H}$; $L_{2 b}=0.4 \mathrm{H} ; L_{4 a}=-0.01 \mathrm{H} ; L_{4 b}=0.05 \mathrm{H}$.

Taking the latter into consideration, according to (8), dependence $L(i(t))$ will assume the form:

$$
L(i(t))=0.8+0.2 \cos (2 \Omega t)+0.4 \sin (2 \Omega t)-0.01 \cos (4 \Omega t)+0.05 \sin (4 \Omega t) \text {. }
$$




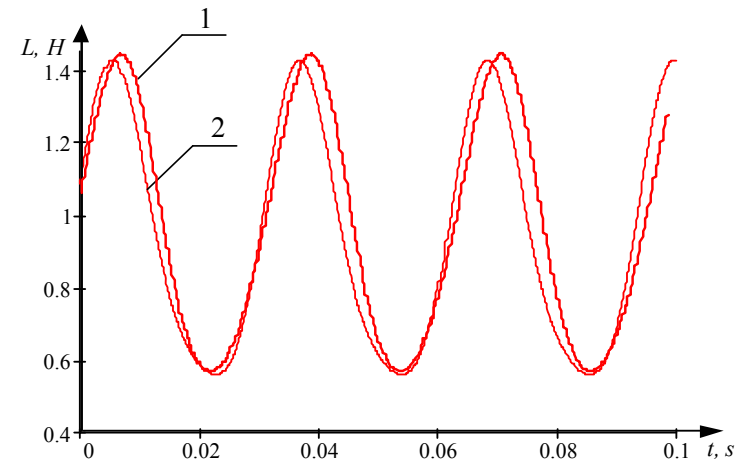

Fig. 5

Curves of time variation of nonlinear inductance are shown in Fig. 5.

Time dependences of inductance variation: $1-$ curve obtained as a result of mathematical modeling; 2 curve calculated according to formula (23).

Difference between calculated dependences and data obtained as a result of modeling is conditioned by the fact that only higher and most significant harmonics were taken into account during calculation. Consequently, to provide more accuracy in calculation it is necessary to take into account more harmonics. However, this, in its turn, results in an increased number of equations and complication of mathematical

calculations.

To determine the approximation coefficient in accordance with power method the system of calculation equations will be obtained from expression:

$$
p(t)=p_{R}(t)+p_{L(i(t))}(t),
$$

where $p_{L(i(t))}(t)=\left(L(i(t)) \frac{d i(t)}{d t}+i(t) \frac{L(i(t))}{d t}\right) i(t)$, and $L(i(t))$ is presented in the form of $(5)$.

The system of identification equations is of the form

$$
\left\{\begin{array}{l}
150=3.1 b_{2}-4.8 b_{4}+1.5 R \\
160=-3385 b_{4}-171.5 b_{0}-875 b_{2}+0.9 R \\
-144=-2273 b_{4}-87 b_{0}-555 b_{2}-1.7 R \\
10.6=1078 b_{2}-511 b_{4}-117 b_{0}-0.09 R
\end{array}\right.
$$

As a result of its solution the following values of parameters were obtained: $R=99 \mathrm{Ohm} ; b_{0}=1.44$;

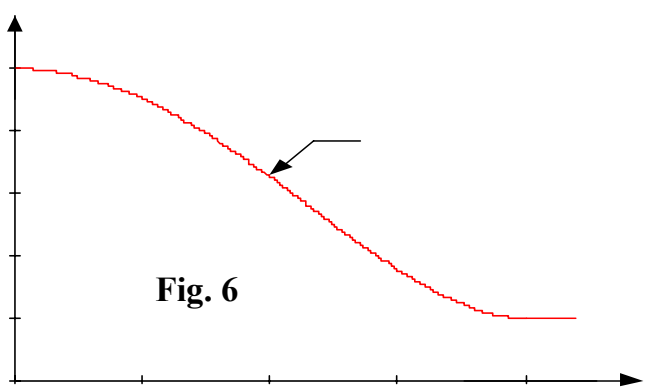

Conclusions.

1. It has been shown that power method, unlike conventional methods of description and determination of nonlinear parameters of alternating current electric circuits, makes it possible to obtain a sufficient number of equations with any number of unknowns. It does not require initial approximations and allows taking into account physical features of nonlinear elements. It has been proposed to use equations of power balance of power harmonics of the source and the consumer as a mathematical basis for solution of identification problems of nonlinear circuits.

Solution of the problem in several stages, i.e. through substitution of a variable component by equivalent EMF, provides the possibility to analyze processes of energy conversion in the circuit, power losses, its dissipation and generation.

2. It has been obtained that the use of this method makes it possible to consider electric circuit elements separately. It simplifies the analysis of power processes by formulation of identification equations for each element separately.

3. Procedure of calculation of nonlinearity parameters in alternating current electric circuits with the use of power method has been developed. 
4. Power method efficiency was verified, taking an electric circuit with nonlinear inductance as an example, by comparison of data obtained as a result of modeling and calculated data. The analysis showed that calculation error is within the admissible limits. Accuracy can be improved taking into consideration higher harmonics in current signals and in the expression describing the nonlinear element.

1. Rodkin D.Y. On the inconsistency of some theory of the energy processes with Tellegen's theorem // Problems of automated electric drive. Theory and practice. - 2010. - Vol. 28. - Pp. 127-135. (Rus)

2. Engberg J., Larsen T. Theory of Linear and Nonlinear Circuits. - Denmark: The Univesity of Aalborg, 1995.

3. Heitbrink A., Beyer A. A new approach for the calculation of nonlinear magnetic circuits // Journal of Applied Physics. - 2009. - Vol. 73. - Pp. 6793-6795.

4. Douglas Wilhelm Harder, Math M. Numerical Methods for Electrical and Computer Engineers. - Canada, Ontario: University of Waterloo, 2005.

5. Salon S.J. Finite Element Analysis of Electrical Machines. - Kluwer Academic Publishers, 1995.

6. Wcislik M. Powers Balances in AC Electric Circuit with Nonlinear Load // IEEE Transactions on Industry Applications, Harmonics and Quality of Power (ICHQP). - 2010. - Pp. 1-6.

7. Zghoul F.N., Egolf D. Analyzing nonlinear circuits using a modified harmonic balance method // IEEE Synthesis, Modeling, Analysis and Simulation Methods and Applications to Circuit Design (SMACD). - 2012. - Pp. 213 -216.

8. Depenbrock M., Staudt V., Wrede H. A theoretical investigation of original and modified instantaneous power theory applied to four-wire systems // IEEE Transactions on Industry Applications. - 2003. - Vol. 39. - No 4. - Pp. 1089-1095.

9. Rodkin D., Mosyundz D., Cherniy A., Korenkova T. Enhancement capabilities of energy method in task of identification nonlinearity of electromechanical system // Electromechanical and energy saving systems. - 2012. - Vol. 18. - No 2. - Pp. 10-17. (Rus)

10. Rodkin D.I., Byalobrzheskii A.V., Lomonos A.I. Energy processes in grid with polyharmonic voltage and current // Russian Electrical Engineering. - 2004. - No 75(6). - Pp. 60-69.

11. Meisel J. Principles of Electromechanical Energy Conversion. - New York: McGraw-Hill, 1996.

12. Chen W.K. Feedback, Nonlinear, and Distributed Circuits. - USA, Chicago: CRC Press, 2009.

\title{
УДК 621.313 \\ ИСПОЛЬЗОВАНИЕ ЭНЕРГЕТИЧЕСКОГО МЕТОДА ДЛЯ ИДЕНТИФИКАЦИИ ПАРАМЕТРОВ НЕЛИНЕЙНОСТЕЙ
}

М.В. Загирняк, докт.техн.наук, Д. Мосюндз, Д.И. Родькин, докт.техн.наук

Кременчугский национальный университет имени Михаила Остроградского,

Институт электромеханики, энергосбережения и систем управления,

ул. Первомайская, 20, Кременчуг, 39600, Украина.

e-mail: mzagirn@kdu.edu.ua, e-mail: darya_mosyundz@mail.ru

Предложена методика расчета параметров нелинейностей энергетическим методом, в основе которого лежат уравнения баланса составляющих мгновенной мощности источника и потребителя по каждой отдельной гармонике. Показано, что такой подход позволяет получить необходимое количество уравнений для определения параметров нелинейностей. Методика проверена на примере расчета параметров простейшей электрической цепи с нелинейной индуктивностью. Библ. 12, рис. 6.

Ключевые слова: нелинейный элемент, мгновенная мощность, энергетический метод, уравнения энергетического баланса мгновенных компонентов.

\author{
УДК 621.313 \\ М.В. Загірняк, докт.техн.наук, Д. Мосюндз, Д.Й. Родькін, докт.техн.наук \\ Кременчуцький національний університет імені Михайла Остроградського, \\ Інститут електромеханіки, енергозбереження і систем управління, \\ вул. Першотравнева, 20, Кременчук, 39600, Україна. \\ e-mail: mzagirn@kdu.edu.ua, e-mail: darya_mosyundz@mail.ru
}

ВИКОРИСТАННЯ ЕНЕРГЕТИЧНОГО МЕТОДУ ДЛЯ ІДЕНТИФІКАЩЇ ПАРАМЕТРІВ НЕЛІНІЙНОСТЕЙ

Запропоновано методику розрахунку параметрів нелінійностей енергетичним методом, в основі якого лежать рівняння балансу складових миттєвої потужності джерела і споживача за кожною окремою гармонікою. Показано, шуо такий підхід дозволяє отримати необхідну кількість рівнянь для визначення параметрів нелінійностей. Методика перевірена на прикладі розрахунку параметрів найпростішого електричного кола з нелінійною індуктивністю. Бібл. 12, рис. 6.

Ключові слова: нелінійний елемент, миттєва потужність, енергетичний метод, рівняння енергетичного балансу миттєвих компонентів.

Надійшла 11.04.2016

Остаточний варіант 16.12.2016 